\title{
RNA-binding proteins and translational regulation in axons and growth cones
}

\author{
Hanna Hörnberg and Christine Holt* \\ Department of Physiology Development and Neuroscience, University of Cambridge, Cambridge, UK
}

\section{Edited by:}

Jernej Ule, MRC Laboratory of

Molecular Biology, UK

\section{Reviewed by:}

Rossen Donev, Swansea University, UK

Michael A. Kiebler, Ludwig

Maximilians University of Munich,

Germany

\section{*Correspondence:}

Christine Holt, Department of Physiology Development and

Neuroscience, University of

Cambridge, Anatomy Building,

Downing Street, Cambridge, CB2

3DY, UK.

e-mail:ceh33@cam.ac.uk
RNA localization and regulation play an important role in the developing and adult nervous system. In navigating axons, extrinsic cues can elicit rapid local protein synthesis that mediates directional or morphological responses. The mRNA repertoire in axons is large and dynamically changing, yet studies suggest that only a subset of these mRNAs are translated after cue stimulation, suggesting the need for a high level of translational regulation. Here, we review the role of RNA-binding proteins (RBPs) as local regulators of translation in developing axons. We focus on their role in growth, guidance, and synapse formation, and discuss the mechanisms by which they regulate translation in axons.

Keywords: RNA-binding proteins, local translation, axon outgrowth, axon guidance, synapse formation

\section{INTRODUCTION}

Spatial localization of mRNA is a well conserved mechanism for restricting gene expression to a specific subcellular site in many cell types across animal and plant phyla (Condeelis and Singer, 2005; Holt and Bullock, 2009). In neurons, localization and translational regulation of mRNA plays a key function in dendrites and post-synaptic compartments (Bramham and Wells, 2007), and mounting evidence points to a similarly important role in axons (Jung et al., 2012). The response to several guidance cues require local protein synthesis in the tip of the growing axon, the growth cone (GC), (Campbell and Holt, 2001; Wu et al., 2005; Leung et al., 2006; Piper et al., 2006; Yao et al., 2006) and axonal mRNA translation is critical for axon survival (Hillefors et al., 2007; Cox et al., 2008; Yoon et al., 2012) and regeneration (Zheng et al., 2001; Verma et al., 2005). A large number of mRNAs are found in both growing (Andreassi et al., 2010; Zivraj et al., 2010) and mature axons (Taylor et al., 2009; Gumy et al., 2011), with some transcripts restricted to specific neuronal subtypes, axonal compartments (Zivraj et al., 2010), or developmental time points (Zivraj et al., 2010; Gumy et al., 2011).

Different guidance cues ultimately lead to the translation of distinct subsets of mRNAs (Wu et al., 2005; Leung et al., 2006; Piper et al., 2006; Yao et al., 2006), yet, puzzlingly, cause an increase in the activity of markers of global translation in the GC (Campbell and Holt, 2001; Leung et al., 2006; Piper et al., 2006). This begs the question of how translation of specific mRNAs is locally regulated. The specificity is likely mediated, at least in part, via RNA-binding proteins (RBPs). RBPs comprise a large family of proteins that form ribonucleoprotein (RNP) complexes with their target mRNAs and can act as cytoskeletal adaptors and/or translational silencers to transport their cargo to subcellular locations (Besse and Ephrussi, 2008). Once on site, RBPs can either act as translational repressors or activators of their mRNA targets, thus providing a way to control translation spatially and temporally. Here, we review the role of RBPs as regulators of local protein synthesis in the axon during development, from axon elongation, to axon guidance and synapse formation in target-arrived axons. Lastly, we discuss the possible mechanism by which RBPs regulate the specificity of local translation in axons and GCs.

\section{AXONAL GROWTH CONE RBPS REVEALED BY PROTEOMIC ANALYSIS}

RBPs are widely expressed in the central nervous system (CNS) and many exhibit region-specific expression in the developing brain, suggesting that RBPs may play a major role in establishing cell-type specific function during development (McKee et al., 2005). However, most of our knowledge of the function of RBPs in neurons stems from distinct cellular or dendritic compartments, and although RBPs have been found in axons (Zhang et al., 2001; Rossoll et al., 2002, 2003; Leung et al., 2006; Price et al., 2006; Yao et al., 2006; Christie et al., 2009; Akten et al., 2011), their full repertoire has not been determined and little is known about their abundance and distribution in axonal compartments.

An unbiased proteomic study has been performed recently on GCs from whole rat embryonic brain (Estrada-Bernal et al., 2012) and we have interrogated this dataset to determine the repertoire of RBPs. Interestingly, our analysis indicates that about $1 \%$ of all GC proteins are putative RBPs. This estimate is likely to be an under-representation because the experimental design of the study favors proteins expressed in the majority of GCs without taking into account any regional-or cell-specific expression of RBPs. Consistent with this line of reasoning, RBPs previously identified in axons, such as HuD (Akten et al., 2011; Fallini et al., 2011), the Fragile $X$ mental retardation protein (FMRP) (Antar et al., 2006; Price et al., 2006; Christie et al., 2009; Akins et al., 
2012) and cytoplasmic polyadenylation element-binding protein (CPEB) (Kundel et al., 2009) were not identified in this screen, indicating that these RBPs may only be present in specific subsets of axons. Nonetheless, the study provides unparalleled insights into the repertoire of GC RBPs. Out of the 22 putative RBPs identified, only two, zipcode binding protein 1 (ZBP1, also known as IMP-1 and Vg1RBP) and survival motor neuron 1 (SMN) have previously been identified in GCs (Zhang et al., 2001, 2003, 2006; Leung et al., 2006; Fallini et al., 2011; Welshhans and Bassell, 2011). The single largest group of RBPs, comprising about 50\% of all RBPs identified in the GCs, were the heterogenous nuclear ribonucleoprotein family (hnRNP) family of RBPs, a large family of RBPs that varies greatly in both function and structure (Han et al., 2010). To date, only one family member has previously been identified in axons and GCs (Rossoll et al., 2002, 2003; Glinka et al., 2010), but their striking enrichment in the GC proteome suggests that they may have a widespread role in developing axons. Members of the hnRNP family have also been identified in post-synaptic densities (Jordan et al., 2004; Zhang et al., 2012), indicating that they may serve key functions in both pre- and post-synaptic compartments. However, it is worth nothing that the hnRNPs enriched in post-synaptic densities differs from the hnRNPs most abundant in GCs (Zhang et al., 2012).

Of the other RBPs identified in GCs, four were RNArecognition motif (RRM) containing proteins previously identified for their role in splicing and transcription (Imai et al., 1993; Patturajan et al., 1998; Kataoka et al., 2000; Guo et al., 2003; Cazalla et al., 2005; Chuang et al., 2011; Albers et al., 2012). Many hnRNPs also have known nuclear functions, and it is interesting to note that the majority of RBPs identified in this study, including hnRNP K (Expert-Bezancon et al., 2002; Lynch et al., 2005; Stains et al., 2005), U (Kukalev et al., 2005; Huelga et al., 2012), F (Min et al., 1995; Martinez-Contreras et al., 2006; Huelga et al., 2012), E1 (Kim et al., 2005; Akker et al., 2007), H1 SMN (Pellizzoni et al., 2002) and RNA binding motif protein 8a (RBM8a, also known as Y14) (Kataoka et al., 2000; Chuang et al., 2011; Albers et al., 2012), have well-established nuclear functions as regulators of splicing and transcription. In fact, of all RBPs found in GCs, only ZBP1 is best known for its cytoplasmic function. This raises the intriguing possibility that many neuronal RBPs may have a dual role both in the nucleus and cytosol. Interestingly, both proteins and mRNAs of splicing factors have been found in GCs (Zivraj et al., 2010; Estrada-Bernal et al., 2012), suggesting that axonal mRNA regulation may be more complex than previously thought.

\section{RBP-MEDIATED LOCAL REGULATION OF AXON GROWTH, GUIDANCE, AND SYNAPSE FORMATION}

While the role of RBPs in dendrites and post-synaptic compartments has traditionally received more attention (Bramham and Wells, 2007; Swanger and Bassell, 2011), several studies are starting to focus on the role of RBPs in axons. Some of these RBPs, like hnRNP R and SMN, appear to localize mainly in axons outside of the nucleus. Others, such as FMRP and ZBP1, have both dendritic and axonal functions. In this section, we review the role RBPs play as local regulators during axon growth, guidance, and synapse formation (Table $\mathbf{1}$ ).

\section{AXON GROWTH}

Axon outgrowth and the continuous regulation of axon growth are key steps during axon guidance and regeneration. Two RBPs associated with neurodegenerative disorders affecting motor neurons have been implicated as local regulators of axon growth suggesting that translational regulation in axons during this process may be broadly crucial for the survival and health of motor neurons. These RBPs are SMN and TDP-43.

$\mathrm{SMN}$ is a ubiquitously expressed RBP most known for its role in assembling small nuclear ribonucleoprotein (snRNP) complexes involved in splicing (Burghes and Beattie, 2009). Depletion of SMN is the cause of spinal muscular atrophy (SMA) and loss of SMN leads to degeneration of motor neurons. However, why the loss of a ubiquitously expressed gene causes a specific defect in motor neurons is not well understood. SMN has been detected in axons (Rossoll et al., 2002; Zhang et al., 2003, 2006; Fallini et al., 2011), and cultured motor neurons from a SMN mouse model display axonal defects including reduced axon growth, smaller GCs and reduced levels of $\beta$-actin mRNA in the axon and GC (Rossoll et al., 2003). In zebrafish and Xenopus tropicalis, knockdown of SMN leads to truncated motor neuron development in vivo (McWhorter et al., 2003; Ymlahi-Ouazzani et al., 2010). SMN can interact with several other RBPs (Mourelatos et al., 2001; Rossoll et al., 2002; Wang et al., 2002; Piazzon et al., 2008), and is thought to regulate translation indirectly via these interactions as SMN itself lacks any known RNA-binding domains. One of these RBPs, hnRNP R, is reduced in GCs and axons of cultured motor neurons lacking SMN (Rossoll et al., 2003), and depletion of hnRNP R in zebrafish gives a similar phenotype to SMN knockdown (Glinka et al., 2010). hnRNP R can associate with $\beta$-actin $3^{\prime}$ UTR and co-localizes with $\beta$-actin in GCs (Glinka et al., 2010). Knockdown of hnRNP $\mathrm{R}$ leads to a decrease in $\beta$-actin mRNA levels in GCs but no change in total mRNA levels, suggesting that hnRNP R specifically alters the subcellular location of $\beta$-actin mRNA. Overall, these findings suggest that SMN and hnRNP R co-regulate $\beta$-actin mRNA localization and translation in the distal axon during axon growth in motor neurons.

The TAR DNA binding protein 43, TDP-43, is also implicated in axonal regulation of motor neuron outgrowth. TDP-43 is mostly a nuclear DNA/RNA-binding protein involved in many parts of mRNA post-transcriptional regulation such as splicing, stability, and transport (Lee et al., 2012). TDP-43 is implicated in neurodegenerative diseases such as amyotrophic lateral sclerosis (ALS) and frontotemporal lobar degeneration (FTLD-U) where TDP-43 is found in large insoluble granules in the cytoplasm, but the pathogenesis of these granules is not clear. Apart from its nuclear location, TDP-43 has been found in axons of motor neurons where it co-localizes with other RBPs (Fallini et al., 2012). Axonal TDP-43 levels increase after BDNF stimulation in cultured motor neurons, and depletion of TDP-43 increases axon length and branching (Fallini et al., 2012). However, in mouse neuroblastoma neuro-2a cells TDP-43 depletion inhibits neurite outgrowth (Iguchi et al., 2009), and in zebrafish embryos zTDP-43 depletion causes reduced axon length in motor neurons (Kabashi et al., 2010), suggesting that TDP-43 may have different roles during neuronal development in different neuronal populations and species. 
Table 1 | RBPs in axons.

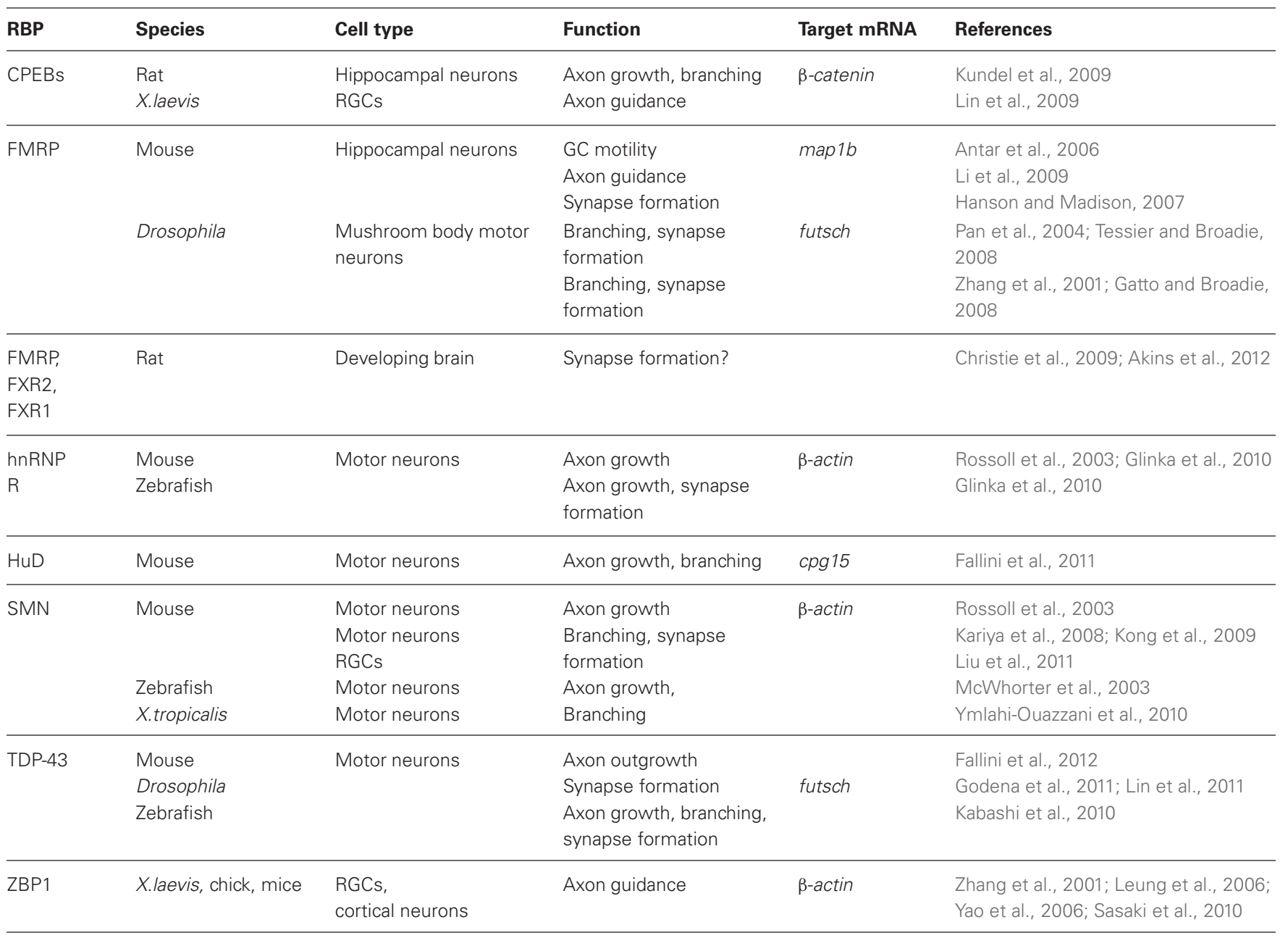

\section{AXON GUIDANCE}

Local protein synthesis plays a key role during axon guidance in vitro (Campbell and Holt, 2001; Wu et al., 2005; Leung et al., 2006; Piper et al., 2006; Yao et al., 2006) and in vivo (Leung et al., 2013) and although many mRNAs have been identified in axons (Taylor et al., 2009; Andreassi et al., 2010; Zivraj et al., 2010; Gumy et al., 2011), the identity of those that are actively translated and how they are regulated is less clear. RBPs are needed to transport mRNA to the GCs, but what regulatory role they play in the GCs during axon guidance is not well known. Some RBPs, depicted in Figure 1, can mediate the response to guidance cues by regulating local translation of their target mRNAs. ZBP1 was the first RBP found to regulate axon guidance, and its local regulation of $\beta$-actin $\mathrm{mRNA}$ in response to guidance cues is conserved in several species (Zhang et al., 2001; Leung et al., 2006; Welshhans and Bassell, 2011). In Xenopus laevis, the ZBP1 ortholog, Vg1RBP, mediates turning toward the attractive guidance cue Netrin-1 (Leung et al., 2006) and to brain-derived neurotrophic factor, BDNF (Yao et al., 2006). Stimulation of retinal ganglion cell (RGC) axonal GCs by a Netrin-1 gradient induces polarized movement of Vg1RBP toward the Netrin-1 source, and this is accompanied by an asymmetrical increase in activated
eIF-4E-binding protein 1 (4EBP1) and $\beta$-actin translation (Leung et al., 2006). A BDNF gradient also leads to asymmetric $\beta$-actin and Vg1RBP localization in spinal cord neuron GCs, and preventing the $\beta$-actin-ZBP1 interaction abolishes both $\mathrm{Ca}^{2+}$-mediated attraction and repulsion (Yao et al., 2006). This suggests that $\mathrm{ZBP} 1$ is crucial for regulating both the translation and spatial location of $\beta$-actin during GC turning. Together these two studies gave the first insight into how an RBP can spatially restrict translation in the GC. Translational dysregulation of $\beta$-actin can cause morphological defects in axons of several types of neurons (Zhang et al., 2001; Huttelmaier et al., 2005; Leung et al., 2006; Yao et al., 2006; Welshhans and Bassell, 2011), and several axonal RBPs have $\beta$-actin mRNA among their targets (Zhang et al., 2001; Rossoll et al., 2003; Huttelmaier et al., 2005; Leung et al., 2006; Glinka et al., 2010; Welshhans and Bassell, 2011), suggesting that translational regulation of $\beta$-actin may be of particular importance in axons. In dendrites, ZBP1-mediated dysregulation of $\beta$-actin perturbs branch development (Perycz et al., 2011), but whether or not ZBP1 has a similar function in axonal branching is not known.

FMRP is best known for its role as a translational regulator in the post-synaptic compartment, but it is also gaining attention 


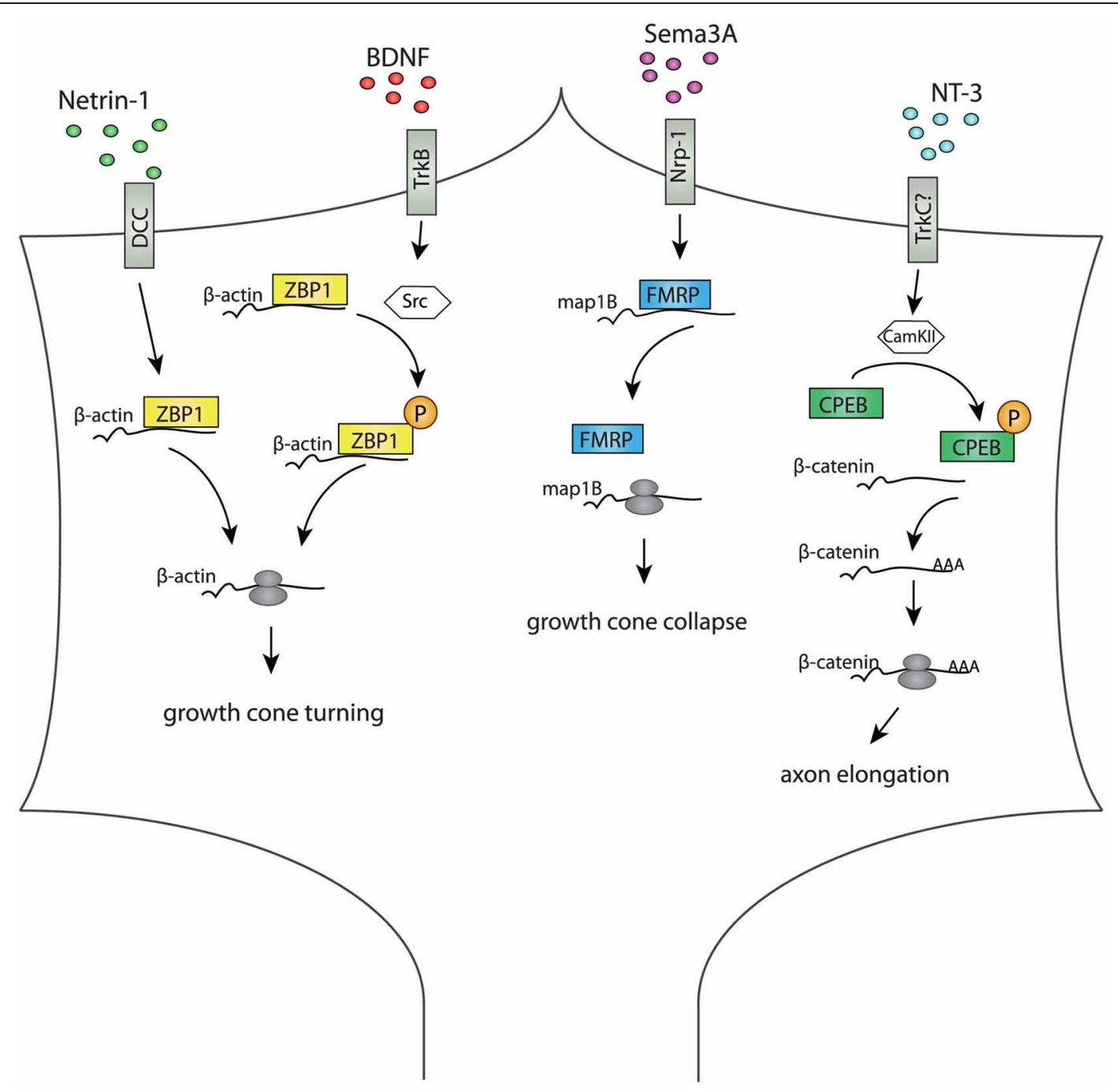

FIGURE 1 | Diagram summarizing RBP-mediated regulation of different cue-stimulated responses in axonal growth cones. In the growth cone, RBPs mediate translation of specific mRNAs after cue stimulation. Netrin-1 induces ZBP1 localization and translation of $\beta$-actin close to the source of Netrin-1, and this is crucial for growth cone turning (Leung et al., 2006; Lin and Holt, 2007). BDNF induces Src-mediated ZBP1 phosphorylation, $\beta$-actin translation and growth cone turning toward the
BDNF source (Yao et al., 2006; Sasaki et al., 2010). Growth cone collapses and Map1B mRNA translation in response to Sema3a is attenuated in axons depleted of FMRP, suggesting a role for FMRP in Sema3A-mediated axon guidance (Li et al., 2009). NT3 induces CamKII mediated phosphorylation of CPEB1, which activates polyadenylation and translation of $\beta$-catenin mRNA crucial for axon elongation and branching (Kundel et al., 2009). for its role in axons (Christie et al., 2009; Deng et al., 2011; Till et al., 2011; Akins et al., 2012). FMRP is present in axons and GCs (Antar et al., 2006), and knockdown of FMRP in hippocampal neurons leads to reduced GC motility, excess filopodia (Antar et al., 2006), and attenuated collapse in response to the repulsive guidance cue Semaphorin 3A (Sema3A) (Li et al., 2009). Sema3A stimulation increases the levels of phosphorylated eukaryotic translation initiation factor eIF4E and MAP1b translation in distal axons, but this increase is abolished in FMRP deficient neurons ( $\mathrm{Li}$ et al., 2009), suggesting a role for FMRP in axons during Sema3Amediated GC steering via regulation of MAP1b translation in the GC.

\section{AXON ARBORIZATION AND SYNAPSE FORMATION}

Translational regulation is crucial for synaptic function, and a number of cognitive disorders are linked to mRNA dysregulation. For example, Fragile X syndrome (FXS), the most common form of inherited mental retardation, is caused by the loss of FMRP function and subsequent dysregulation of its target mRNAs (Bassell and Warren, 2008). Although FXS is thought to be caused mainly by the loss of FMRP function in the postsynaptic compartment, several lines of evidence suggest that FMRP may also have a pre-synaptic role at the synapse. FMRP binds to many mRNAs encoding pre-synaptic proteins (Akins et al., 2009; Darnell et al., 2011), and several pre-synaptic proteins are differentially regulated in fmrl knockout (KO) mice 
(Klemmer et al., 2011). In Drosophila, the mushroom body neurons of dFMRP null mutants have over-branched axonal arbors and form abnormal synapses, (Pan et al., 2004; Tessier and Broadie, 2008), and abnormal pre-synaptic structures at the neuromuscular junction (NMJ) (Zhang et al., 2001; Gatto and Broadie, 2008). Furthermore, in a mosaic mouse model of FXS, neurons lacking FMRP function form fewer synaptic connections than wild type neurons, suggesting that pre-synaptic FMRP function may determine the likelihood of forming a synapse (Hanson and Madison, 2007). Pre-synaptic expression of FMRP appears restricted to a subset of neuronal circuits where it is present in granules (Fragile X granules; FXGs) in association with its paralogs FXR2p and FXR1p (Christie et al., 2009; Akins et al., 2012). The expression of these granules peak during the time of synapse formation and pruning (Christie et al., 2009; Akins et al., 2012), indicating a possible pre-synaptic role for FMRP and its paralogs during synapse formation in a subset of axon population.

Disruption of SMN also causes pre-synaptic abnormalities. In a mouse model of SMA, axons at the NMJ terminals are poorly arborized and display abnormal neurofilament accumulation in the nerve terminals (Kariya et al., 2008). Furthermore, SMN knockdown causes abnormal synaptic transmission (Kariya et al., 2008; Kong et al., 2009), lower synaptic vesicle density at the presynaptic site (Kong et al., 2009) and a reduction of $\mathrm{Ca}_{\mathrm{v}} 2.2 \mathrm{Ca}^{2+}$ channels at the NMJ (Jablonka et al., 2007). Interestingly, knockdown of hnRNP R leads to a similar phenotype (Glinka et al., 2010), indicating that SMN and hnRNP R may co-regulate translation both during axon growth and synapse formation. SMNs' function has mostly been studied in motor neurons, but similar defects have been reported in the retina of a mouse SMA model (Liu et al., 2011), suggesting that perhaps SMN has a conserved role in axon elongation and connectivity in several axon populations. SMN may regulate synapse formation partially via co-regulation of the candidate plasticity-related gene 15 (cpg15), an activity-regulated protein with key functions during branching and synaptogenesis in the NMJ. SMN can interact with $\mathrm{HuD}$ (Akten et al., 2011; Fallini et al., 2011), an RBP known to bind to and regulate cpg15 expression (Wang et al., 2011), and both SMN and $\mathrm{HuD}$ co-localize with cpg15 in axons. Disruption of SMN function reduces the amount of cpg15 mRNA, and overexpression of cpg15 partially rescues the SMA phenotype in a zebrafish model (Akten et al., 2011). Together these studies suggest a crucial role for $\mathrm{SMN}$ and $\mathrm{HuD}$ mediated cpg15 mRNA regulation in axons during synapse formation at the NMJ.

TDP-43 has also been shown to cause defects in axonal branching and synapse formation at the NMJ. Depletion of TDP-43 causes an increase in synaptic boutons at the NMJ in Drosophila (Lin et al., 2011), and immature and excessive branching in zebrafish (Kabashi et al., 2010). In Drosophila, the defects are associated with a decrease in the microtubule stabilizing protein futsch, a MAP1B ortholog. dTDP-43 can interact directly with futsch mRNA, and dTDP-43s RNA-binding property is essential for its function in synapse formation (Godena et al., 2011). Furthermore, dTDP-43 depletion decreases futsch protein in distal boutons, but futsch mRNA levels was unchanged, suggesting a role for dTDP-43 in translational regulation of futsch (Godena et al., 2011).

\section{TRANSLATIONAL REGULATION BY RBPS IN THE AXON AND GROWTH CONE}

How do RBPs repress translation in the GC, and how is translation activated? Translational repressors are found in RNPs (Kim-Ha et al., 1995; Nakamura et al., 2004; Paquin et al., 2007) and when bound to their targets these repressors can regulate translation by either blocking translation elongation, or, most often, translational initiation. ZBP1 can block translation initiation by inhibiting recruitment of the 60S subunit (Huttelmaier et al., 2005), FMRP is thought to block translation elongation by recruiting the eIF4E-binding protein CYFIP1 (Napoli et al., 2008) and the post-synaptic RBP, Pumilio, regulates the abundance of eIF4E at the NMJ (Menon et al., 2004).

RBPs may also regulate translation via modulating the length of the poly(A) tail of mRNA. CPEB controls translation by polyadenylation and directly binds the CPE sequence in the 3'UTR of its target mRNAs (Richter, 2007). Blocking polyadenylation attenuates the collapse response to Sema3A in Xenopus retinal axons (Lin et al., 2009), and blocking CPEBl's function in hippocampal neurons causes a reduction in NT3-induced $\beta$-actin translation in the GC, possible via $\mathrm{Ca}^{2+}$ mediated inositol triphosphate (IP3) and $\mathrm{Ca}^{2+} /$ calmodulin-dependent protein kinsase II (CamKII) activation (Kundel et al., 2009). This suggests that regulation of poly(A) tail length may be a common way for guidance cues to regulate translation of specific mRNAs.

Stimulation of GCs with protein synthesis-inducing guidance cues, such as Netrin-1 and Sema3A, leads to the activation of global translation, as indicated by $4 \mathrm{EBP} 1$ and $\mathrm{mTOR}$ activation, yet they each stimulate the translation of a distinct set of mRNAs (Wu et al., 2005; Leung et al., 2006). Furthermore, guidance cues can stimulate translation globally while repressing specific transcripts (Yoon et al., 2012), and both translation reporters and newly synthesized protein can be localized to specific compartments in the GC (Leung et al., 2006; Yao et al., 2006). How translational specificity is achieved and how it is spatially localized in the GC is largely unknown.

Signal-mediated phosphorylation of RBPss present in the GC may provide a way to regulate translation of specific mRNAs. BDNF induces Src-mediated phosphorylation of ZBP1, and blocking this step attenuates local $\beta$-actin translation and GC turning (Sasaki et al., 2010). Src is activated asymmetrically toward the BDNF source (Yao et al., 2006), indicating that localized activation of distinct set of RBPs may provide both spatial and temporal control over translation. FMRP activity is also regulated by phosphorylation (Narayanan et al., 2008; Muddashetty et al., 2011; Coffee et al., 2012), suggesting that phosphorylation could be a common mechanism for releasing RBP-mediated repression upon cue stimulation.

RBPs can also mediate translational regulation via small noncoding RNAs such as microRNAs (miRNAs). miRNAs can associate with RBPs (Schratt et al., 2006; Edbauer et al., 2010), and RBPs are known to regulate the abundance of miRNAs (Michlewski et al., 2008; Xu et al., 2008, 2011; Xu and Hecht, 2011). In dendrites, there is evidence that miRNAs can act locally as translational repressors (Schratt et al., 2006). miRNAs and RNA-induced silencing complex (RISC) components have been 
found to associate with FMRP (Caudy et al., 2002; Jin et al., 2004; Muddashetty et al., 2011), and FMRP may depend on miRNAs to repress some of its targets (Muddashetty et al., 2011). HuR can interfere with miRNA-mediated repression in cell culture, both as an antagonist of miRNA repression (Bhattacharyya et al., 2006) and in a cooperative manner to help facilitate repression (Kim et al., 2009). Interaction studies suggest that HuR may regulate the efficiency of several miRNAs (Mukherjee et al., 2011), and it would be interesting to see if its neuronal family member, $\mathrm{HuD}$, can act in a similar fashion. miRNAs have been found in the distal axon (Natera-Naranjo et al., 2010; Han et al., 2011; DajasBailador et al., 2012), and seem to play a role in guidance cue responses. Knockdown of Dicer leads to axon guidance defects in the visual system in mice (Pinter and Hindges, 2010), and knockdown of the miRNA miR-124 leads to guidance defects of RGC axons caused by an attenuated response to Sema3A (Baudet et al., 2012). However, miRNA-RBP mediated regulation is a relatively novel concept and whether or not RBPs can regulate miRNA repression in axons and GCs is not yet known.

Another intriguing possibility is that receptor-ribosome interactions may be used to restrict translation spatially and confer additional translation specificity. The Netrin-1 receptor, DCC, can interact directly with the translational machinery by forming complexes with ribosomal subunits. This interaction is disassociated upon Netrin-1 stimulation to promote DCC-mediated translation (Tcherkezian et al., 2010), suggesting a possible mechanism to spatially restrict cue-induced translation to a specific subcellular compartment.

\section{FUTURE PERSPECTIVES}

RBPs are beginning to emerge as important players in the presynaptic compartment during the building of neuronal circuits, but many questions still remain. The list of axonal RPBs is still incomplete, and little is known of their mRNA targets in axons. New techniques such as crosslinking immunoprecipitation (CLIP) (Ule et al., 2005) and high throughput sequencingCLIP (HITS-CLIP) (Licatalosi et al., 2008) will be valuable in future studies for identifying RBP-mRNA complexes in different axon populations and developmental time points. Moreover, further studies on the interactions of RBPs with other posttranscriptional regulatory pathways are needed to help gain insight into how translational specificity is achieved in the GC. For example, it will be important to investigate if guidance receptor coupling to the translational machinery (Tcherkezian et al.,

\section{REFERENCES}

Akins, M. R., Berk-Rauch, H. E., and Fallon, J. R. (2009). Presynaptic translation: stepping out of the postsynaptic shadow. Front. Neural Circuits 3:17. doi: 10.3389/neuro.04.017. 2009

Akins, M. R., Leblanc, H. F., Stackpole, E. E., Chyung, E., and Fallon, J. R. (2012). Systematic mapping of fragile $\mathrm{X}$ granules in the mouse brain reveals a potential role for presynaptic FMRP in sensorimotor functions. J. Comp. Neurol. 520, 3687-3706.

Akker, S. A., Misra, S., Aslam, S., Morgan, E. L., Smith, P. J., Khoo, B., et al. (2007). Pre-spliceosomal binding of U1 small nuclear ribonucleoprotein (RNP) and heterogenous nuclear RNP E1 is associated with suppression of a growth hormone receptor pseudoexon. Mol. Endocrinol. 21, 2529-2540.

Akten, B., Kye, M. J., Hao Le, T., Wertz, M. H., Singh, S., Nie, D., et al. (2011). Interaction of survival

2010) is a common way of restricting translation locally, and to understand the interplay between other pathways such as miRNAs, RBP phosphorylation and mRNA polyadenylation in regulating the spatiotemporal control of local protein synthesis in response to extrinsic cues.

The observation that many axonal RBPs are best known for their nuclear roles suggests that some axonal RBPs may have dual functions in the nucleus and cytosol. Nuclear mRNA processing is important for subsequent cytosolic localization (Giorgi and Moore, 2007), and the axonal and nuclear localization of some RBPs may provide a platform to coordinate pre-mRNA processing and cytosolic translational regulation (Bava et al., 2013). The presence of splice-regulating RBPs in axons suggests the intriguing possibility that some pre-mRNA processing may occur locally in axons. Indeed, cytoplasmic splicing has been identified in neurons (Bell et al., 2010), and splice components localized to dendrites retain their ability to splice RNA (Bell et al., 2010). Splice factors have been found in GCs (Estrada-Bernal et al., 2012), but whether they are involved in splicing or other processes is not known.

Finally, although it is increasingly clear that local translation occurs in navigating axons and post-synaptic compartments, its role in target-arrived axons is much less understood. Transcripts of synapse-associated proteins are commonly present in axons (Zivraj et al., 2010), and pre-synaptic translation has been implicated in synapse development (Taylor et al., 2013), synaptic plasticity (Yin et al., 2006; Deng et al., 2011; Je et al., 2011; Johnstone and Raymond, 2011; Till et al., 2011) and arborization (Dajas-Bailador et al., 2012; Donnelly et al., 2013). Translational dysregulation is thought to underlie several neurodevelopmental and neurodegenerative disorders (Bear et al., 2004; Liu-Yesucevitz et al., 2011; Santini et al., 2013; Taylor et al., 2013). RBPs such as FMRP, SMN and TDP-43 have all been linked to neurological diseases, and their presence in axons suggests that axonal translation may play a role in disease pathology. Elucidating how presynaptic translation influences synapse formation and the role RBPs play in this process will further deepen our understanding of how neuronal circuits are formed and maintained in the developing brain.

\section{ACKNOWLEDGMENTS}

We would like to thank Marie-Laure Baudet and Paolo Macchi (University of Trento, Italy) for their comments on the manuscript.

of motor neuron (SMN) and $\mathrm{HuD}$ proteins with mRNA cpg15 rescues motor neuron axonal deficits. Proc. Natl. Acad. Sci. U.S.A. 108, 10337-10342.

Albers, C. A., Paul, D. S., Schulze, H., Freson, K., Stephens, J. C., Smethurst, P. A., et al. (2012). Compound inheritance of a lowfrequency regulatory $\mathrm{SNP}$ and a rare null mutation in exon-junction complex subunit RBM8A causes TAR syndrome. Nat. Genet. 44, 435-439, S1-S2.
Andreassi, C., Zimmermann, C., Mitter, R., Fusco, S., De Vita, S., Saiardi, A., et al. (2010). An NGF-responsive element targets myo-inositol monophosphatase-1 mRNA to sympathetic neuron axons. Nat. Neurosci. 13, 291-301.

Antar, L. N., Li, C., Zhang, H., Carroll, R. C., and Bassell, G. J. (2006). Local functions for FMRP in axon growth cone motility and activitydependent regulation of filopodia and spine synapses. Mol. Cell. Neurosci. 32, 37-48. 
Bassell, G. J., and Warren, S. T. (2008). Fragile X syndrome: loss of local mRNA regulation alters synaptic development and function. Neuron 60, 201-214.

Baudet, M. L., Zivraj, K. H., AbreuGoodger, C., Muldal, A., Armisen, J., Blenkiron, C., et al. (2012). miR124 acts through CoREST to control onset of Sema3A sensitivity in navigating retinal growth cones. Nat. Neurosci. 15, 29-38.

Bava, F. A., Eliscovich, C., Ferreira, P. G., Minana, B., Ben-Dov, C., Guigo, R., et al. (2013). CPEB1 coordinates alternative $3^{\prime}$-UTR formation with translational regulation. Nature 495, 121-125.

Bear, M. F., Huber, K. M., and Warren, S. T. (2004). The mGluR theory of fragile X mental retardation. Trends Neurosci. 27, 370-377.

Bell, T. J., Miyashiro, K. Y., Sul, J. Y., Buckley, P. T., Lee, M. T., McCullough, R., et al. (2010). Intron retention facilitates splice variant diversity in calciumactivated big potassium channel populations. Proc. Natl. Acad. Sci. U.S.A. 107, 21152-21157.

Besse, F., and Ephrussi, A. (2008). Translational control of localized mRNAs: restricting protein synthesis in space and time. Nat. Rev. Mol. Cell Biol. 9, 971-980.

Bhattacharyya, S. N., Habermacher, R., Martine, U., Closs, E. I., and Filipowicz, W. (2006). Relief of microRNA-mediated translational repression in human cells subjected to stress. Cell 125, 1111-1124.

Bramham, C. R., and Wells, D. G. (2007). Dendritic mRNA: transport, translation and function. Nat. Rev. Neurosci. 8, 776-789.

Burghes, A. H., and Beattie, C. E. (2009). Spinal muscular atrophy: why do low levels of survival motor neuron protein make motor neurons sick? Nat. Rev. Neurosci. 10, 597-609.

Campbell, D. S., and Holt, C. E. (2001). Chemotropic responses of retinal growth cones mediated by rapid local protein synthesis and degradation. Neuron 32, 1013-1026.

Caudy, A. A., Myers, M., Hannon, G. J., and Hammond, S. M. (2002). Fragile X-related protein and VIG associate with the RNA interference machinery. Genes Dev. 16, 2491-2496.

Cazalla, D., Newton, K., and Caceres, J. F. (2005). A novel SR-related protein is required for the second step of Pre-mRNA splicing. Mol. Cell. Biol. 25, 2969-2980.

Christie, S. B., Akins, M. R., Schwob, J. E., and Fallon, J. R. (2009). The
FXG: a presynaptic fragile $\mathrm{X}$ granule expressed in a subset of developing brain circuits. J. Neurosci. 29, 1514-1524.

Chuang, T. W., Peng, P. J., and Tarn, W. Y. (2011). The exon junction complex component Y14 modulates the activity of the methylosome in biogenesis of spliceosomal small nuclear ribonucleoproteins. J. Biol. Chem. 286, 8722-8728.

Coffee, R. L. Jr., Williamson, A. J., Adkins, C. M., Gray, M. C., Page, T. L., and Broadie, K. (2012). In vivo neuronal function of the fragile $\mathrm{X}$ mental retardation protein is regulated by phosphorylation. Hum. Mol. Genet. 21, 900-915.

Condeelis, J., and Singer, R. H. (2005). How and why does beta-actin mRNA target? Biol. Cell 97, 97-110.

Cox, L. J., Hengst, U., Gurskaya, N. G., Lukyanov, K. A., and Jaffrey, S. R. (2008). Intra-axonal translation and retrograde trafficking of CREB promotes neuronal survival. Nat. Cell Biol. 10, 149-159.

Dajas-Bailador, F., Bonev, B., Garcez, P., Stanley, P., Guillemot, F., and Papalopulu, N. (2012). microRNA9 regulates axon extension and branching by targeting Maplb in mouse cortical neurons. Nat. Neurosci. 15, 697-699.

Darnell, J. C., Van Driesche, S. J., Zhang, C., Hung, K. Y., Mele, A., Fraser, C. E., et al. (2011). FMRP stalls ribosomal translocation on mRNAs linked to synaptic function and autism. Cell 146, 247-261.

Deng, P. Y., Sojka, D., and Klyachko, V. A. (2011). Abnormal presynaptic short-term plasticity and information processing in a mouse model of fragile X syndrome. J. Neurosci. 31, 10971-10982.

Donnelly, C. J., Park, M., Spillane, M., Yoo, S., Pacheco, A., Gomes, C., et al. (2013). Axonally synthesized beta-actin and GAP-43 proteins support distinct modes of axonal growth. J. Neurosci. 33, 3311-3322.

Edbauer, D., Neilson, J. R., Foster, K. A., Wang, C. F., Seeburg, D. P., Batterton, M. N., et al. (2010). Regulation of synaptic structure and function by FMRP-associated microRNAs miR-125b and miR132. Neuron 65, 373-384.

Estrada-Bernal, A., Sanford, S. D., Sosa, L. J., Simon, G. C., Hansen, K. C., and Pfenninger, K. H. (2012). Functional complexity of the axonal growth cone: a proteomic analysis. PLoS ONE 7:e31858. doi: 10.1371/journal.pone.0031858

Expert-Bezancon, A., Le Caer, J. P., and Marie, J. (2002). Heterogeneous nuclear ribonucleoprotein (hnRNP)
$\mathrm{K}$ is a component of an intronic splicing enhancer complex that activates the splicing of the alternative exon $6 \mathrm{~A}$ from chicken betatropomyosin pre-mRNA. J. Biol. Chem. 277, 16614-16623.

Fallini, C., Bassell, G. J., and Rossoll, W. (2012). The ALS disease protein TDP-43 is actively transported in motor neuron axons and regulates axon outgrowth. Hum. Mol. Genet. 21, 3703-3718.

Fallini, C., Zhang, H., Su, Y., Silani, V., Singer, R. H., Rossoll, W., et al. (2011). The survival of motor neuron (SMN) protein interacts with the mRNA-binding protein $\mathrm{HuD}$ and regulates localization of poly(A) mRNA in primary motor neuron axons. J. Neurosci. 31, 3914-3925.

Gatto, C. L., and Broadie, K. (2008). Temporal requirements of the fragile $\mathrm{X}$ mental retardation protein in the regulation of synaptic structure. Development 135, 2637-2648.

Giorgi, C., and Moore, M. J. (2007). The nuclear nurture and cytoplasmic nature of localized mRNPs. Semin. Cell Dev. Biol. 18, 186-193.

Glinka, M., Herrmann, T., Funk, N., Havlicek, S., Rossoll, W., Winkler, C., et al. (2010). The heterogeneous nuclear ribonucleoprotein$\mathrm{R}$ is necessary for axonal betaactin mRNA translocation in spinal motor neurons. Hum. Mol. Genet. 19, 1951-1966.

Godena, V. K., Romano, G., Romano, M., Appocher, C., Klima, R., Buratti, E., et al. (2011). TDP-43 regulates Drosophila neuromuscular junctions growth by modulating Futsch/MAP1B levels and synaptic microtubules organization. PLoS ONE 6:e17808. doi: 10.1371/journal.pone. 0017808

Gumy, L. F., Yeo, G. S., Tung, Y. C., Zivraj, K. H., Willis, D., Coppola, G., et al. (2011). Transcriptome analysis of embryonic and adult sensory axons reveals changes in mRNA repertoire localization. $R N A$ 17, 85-98.

Guo, T. B., Boros, L. G., Chan, K. C., Hikim, A. P., Hudson, A. P., Swerdloff, R. S., et al. (2003). Spermatogenetic expression of RNA-binding motif protein 7 , a protein that interacts with splicing factors. J. Androl. 24, 204-214.

Han, L., Wen, Z., Lynn, R. C., Baudet, M. L., Holt, C. E., Sasaki, Y., et al. (2011). Regulation of chemotropic guidance of nerve growth cones by microRNA. Mol. Brain 4:40. doi: 10.1186/1756-6606-4-40

Han, S. P., Tang, Y. H., and Smith, R. (2010). Functional diversity of the
hnRNPs: past, present and perspectives. Biochem. J. 430, 379-392.

Hanson, J. E., and Madison, D. V. (2007). Presynaptic FMR1 genotype influences the degree of synaptic connectivity in a mosaic mouse model of fragile $\mathrm{X}$ syndrome. J. Neurosci. 27, 4014-4018.

Hillefors, M., Gioio, A. E., Mameza, M. G., and Kaplan, B. B. (2007). Axon viability and mitochondrial function are dependent on local protein synthesis in sympathetic neurons. Cell. Mol. Neurobiol. 27, 701-716.

Holt, C. E., and Bullock, S. L. (2009). Subcellular mRNA localization in animal cells and why it matters. Science 326, 1212-1216.

Huelga, S. C., Vu, A. Q., Arnold, J. D., Liang, T. Y., Liu, P. P., Yan, B. Y., et al. (2012). Integrative genomewide analysis reveals cooperative regulation of alternative splicing by hnRNP proteins. Cell Rep. 1, 167-178.

Huttelmaier, S., Zenklusen, D., Lederer, M., Dictenberg, J., Lorenz, M., Meng, X., et al. (2005). Spatial regulation of beta-actin translation by Src-dependent phosphorylation of ZBP1. Nature 438, 512-515.

Iguchi, Y., Katsuno, M., Niwa, J., Yamada, S., Sone, J., Waza, M., et al. (2009). TDP-43 depletion induces neuronal cell damage through dysregulation of Rho family GTPases. J. Biol. Chem. 284, 22059-22066.

Imai, H., Chan, E. K., Kiyosawa, K., Fu, X. D., and Tan, E. M. (1993). Novel nuclear autoantigen with splicing factor motifs identified with antibody from hepatocellular carcinoma. J. Clin. Invest. 92, 2419-2426.

Jablonka, S., Beck, M., Lechner, B. D., Mayer, C., and Sendtner, M. (2007). Defective Ca2+ channel clustering in axon terminals disturbs excitability in motoneurons in spinal muscular atrophy. J. Cell Biol. 179, 139-149.

Je, H. S., Ji, Y., Wang, Y., Yang, F., Wu, W., and Lu, B. (2011). Presynaptic protein synthesis required for NT-3-induced long-term synaptic modulation. Mol. Brain 4:1. doi 10.1186/1756-6606-4-1

Jin, P., Zarnescu, D. C., Ceman, S., Nakamoto, M., Mowrey, J., Jongens, T. A., et al. (2004). Biochemical and genetic interaction between the fragile X mental retardation protein and the microRNA pathway. Nat. Neurosci. 7, 113-117.

Johnstone, V. P., and Raymond, C. R. (2011). A protein synthesis and nitric oxide-dependent presynaptic enhancement in persistent forms of long-term potentiation. Learn. Mem. 18, 625-633. 
Jordan, B. A., Fernholz, B. D., Boussac, M., Xu, C., Grigorean, G., Ziff, E. B., et al. (2004). Identification and verification of novel rodent postsynaptic density proteins. Mol. Cell Proteomics 3, 857-871.

Jung, H., Yoon, B. C., and Holt, C. E. (2012). Axonal mRNA localization and local protein synthesis in nervous system assembly, maintenance and repair. Nat. Rev. Neurosci. 13, 308-324.

Kabashi, E., Lin, L., Tradewell, M. L., Dion, P. A., Bercier, V., Bourgouin, P., et al. (2010). Gain and loss of function of ALS-related mutations of TARDBP (TDP-43) cause motor deficits in vivo. Hum. Mol. Genet. 19, 671-683.

Kariya, S., Park, G. H., Maeno-Hikichi, Y., Leykekhman, O., Lutz, C., Arkovitz, M. S., et al. (2008). Reduced SMN protein impairs maturation of the neuromuscular junctions in mouse models of spinal muscular atrophy. Hum. Mol. Genet. 17, 2552-2569.

Kataoka, N., Yong, J., Kim, V. N., Velazquez, F., Perkinson, R. A., Wang, F., et al. (2000). Pre-mRNA splicing imprints mRNA in the nucleus with a novel RNA-binding protein that persists in the cytoplasm. Mol. Cell 6, 673-682.

Kim, H. H., Kuwano, Y., Srikantan, S., Lee, E. K., Martindale, J. L., and Gorospe, M. (2009). HuR recruits let-7/RISC to repress c-Myc expression. Genes Dev. 23, 1743-1748.

Kim, S. S., Pandey, K. K., Choi, H. S., Kim, S. Y., Law, P. Y., Wei, L. N., et al. (2005). Poly(C) binding protein family is a transcription factor in mu-opioid receptor gene expression. Mol. Pharmacol. 68, 729-736.

Kim-Ha, J., Kerr, K., and Macdonald, P. M. (1995). Translational regulation of oskar mRNA by bruno, an ovarian RNA-binding protein, is essential. Cell 81, 403-412.

Klemmer, P., Meredith, R. M., Holmgren, C. D., Klychnikov, O. I., Stahl-Zeng, J., Loos, M., et al. (2011). Proteomics, ultrastructure, and physiology of hippocampal synapses in a fragile $\mathrm{X}$ syndrome mouse model reveal presynaptic phenotype. J. Biol. Chem. 286, 25495-25504.

Kong, L., Wang, X., Choe, D. W., Polley, M., Burnett, B. G., Bosch-Marce, M., et al. (2009). Impaired synaptic vesicle release and immaturity of neuromuscular junctions in spinal muscular atrophy mice. J. Neurosci. 29, 842-851.

Kukalev, A., Nord, Y., Palmberg, C., Bergman, T., and Percipalle, P. (2005). Actin and hnRNP U cooperate for productive transcription by RNA polymerase II. Nat. Struct. Mol. Biol. 12, 238-244.

Kundel, M., Jones, K. J., Shin, C. Y., and Wells, D. G. (2009). Cytoplasmic polyadenylation element-binding protein regulates neurotrophin3-dependent beta-catenin mRNA translation in developing hippocampal neurons. J. Neurosci. 29, 13630-13639.

Lee, E. B., Lee, V. M., and Trojanowski, J. Q. (2012). Gains or losses: molecular mechanisms of TDP43mediated neurodegeneration. Nat. Rev. Neurosci. 13, 38-50.

Leung, K. M., Van Horck, F. P., Lin, A. C., Allison, R., Standart, N., and Holt, C. E. (2006). Asymmetrical beta-actin mRNA translation in growth cones mediates attractive turning to netrin-1. Nat. Neurosci. 9, 1247-1256.

Leung, L. C., Urbancic, V., Baudet, M. L., Dwivedy, A., Bayley, T. G., Lee, A. C., et al. (2013). Coupling of NF-protocadherin signaling to axon guidance by cue-induced translation. Nat. Neurosci. 16, 166-173.

Li, C., Bassell, G. J., and Sasaki, Y. (2009). Fragile X mental retardation protein is involved in protein synthesis-dependent collapse of growth cones induced by semaphorin-3A. Front. Neural Circuits 3:11. doi: 10.3389/neuro.04.011.2009

Licatalosi, D. D., Mele, A., Fak, J. J., Ule, J., Kayikci, M., Chi, S. W., et al. (2008). HITS-CLIP yields genomewide insights into brain alternative RNA processing. Nature 456, 464-469.

Lin, A. C., and Holt, C. E. (2007). Local translation and directional steering in axons. EMBO J. 26, 3729-3736.

Lin, A. C., Tan, C. L., Lin, C. L., Strochlic, L., Huang, Y. S., Richter, J. D., et al. (2009). Cytoplasmic polyadenylation and cytoplasmic polyadenylation element-dependent mRNA regulation are involved in Xenopus retinal axon development. Neural Dev. 4:8. doi: 10.1186/1749-8104-4-8

Lin, M. J., Cheng, C. W., and Shen, C. K. (2011). Neuronal function and dysfunction of Drosophila dTDP. PLoS ONE 6:e20371. doi: 10.1371/journal.pone.0020371

Liu, H., Beauvais, A., Baker, A. N., Tsilfidis, C., and Kothary, R. (2011). Smn deficiency causes neuritogenesis and neurogenesis defects in the retinal neurons of a mouse model of spinal muscular atrophy. Dev. Neurobiol. 71, 153-169.

Liu-Yesucevitz, L., Bassell, G. J., Gitler, A. D., Hart, A. C., Klann, E., Richter,
J. D., et al. (2011). Local RNA translation at the synapse and in disease. J. Neurosci. 31, 16086-16093.

Lynch, M., Chen, L., Ravitz, M. J., Mehtani, S., Korenblat, K., Pazin, M. J., et al. (2005). hnRNP K binds a core polypyrimidine element in the eukaryotic translation initiation factor 4E (eIF4E) promoter, and its regulation of eIF4E contributes to neoplastic transformation. Mol. Cell. Biol. 25, 6436-6453.

Martinez-Contreras, R., Fisette, J. F., Nasim, F. U., Madden, R., Cordeau, M., and Chabot, B. (2006). Intronic binding sites for hnRNP A/B and hnRNP F/H proteins stimulate premRNA splicing. PLoS Biol. 4:e21. doi: 10.1371/journal.pbio.0040021

McKee, A. E., Minet, E., Stern, C. Riahi, S., Stiles, C. D., and Silver, P. A. (2005). A genome-wide in situ hybridization map of RNAbinding proteins reveals anatomically restricted expression in the developing mouse brain. BMC Dev. Biol. 5:14. doi: 10.1186/1471-213X5-14.

McWhorter, M. L., Monani, U. R., Burghes, A. H., and Beattie, C. E. (2003). Knockdown of the survival motor neuron (Smn) protein in zebrafish causes defects in motor axon outgrowth and pathfinding. J. Cell Biol. 162, 919-931.

Menon, K. P., Sanyal, S., Habara, Y., Sanchez, R., Wharton, R. P., Ramaswami, M., et al. (2004). The translational repressor Pumilio regulates presynaptic morphology and controls postsynaptic accumulation of translation factor eIF-4E. Neuron 44, 663-676.

Michlewski, G., Guil, S., Semple, C. A., and Caceres, J. F. (2008). Posttranscriptional regulation of miRNAs harboring conserved terminal loops. Mol. Cell 32, 383-393.

Min, H., Chan, R. C., and Black, D. L. (1995). The generally expressed hnRNP F is involved in a neuralspecific pre-mRNA splicing event. Genes Dev. 9, 2659-2671.

Mourelatos, Z., Abel, L., Yong, J., Kataoka, N., and Dreyfuss, G. (2001). SMN interacts with a novel family of hnRNP and spliceosomal proteins. EMBO J. 20, 5443-5452.

Muddashetty, R. S., Nalavadi, V. C., Gross, C., Yao, X., Xing, L., Laur, O., et al. (2011). Reversible inhibition of PSD-95 mRNA translation by miR-125a, FMRP phosphorylation, and mGluR signaling. Mol. Cell 42, 673-688.

Mukherjee, N., Corcoran, D. L., Nusbaum, J. D., Reid, D. W., Georgiev, S., Hafner, M., et al.
(2011). Integrative regulatory mapping indicates that the RNA-binding protein HuR couples pre-mRNA processing and mRNA stability. Mol. Cell 43, 327-339.

Nakamura, A., Sato, K., and HanyuNakamura, K. (2004). Drosophila cup is an eIF4E binding protein that associates with Bruno and regulates oskar mRNA translation in oogenesis. Dev. Cell 6, 69-78.

Napoli, I., Mercaldo, V., Boyl, P. P., Eleuteri, B., Zalfa, F., De Rubeis, S., et al. (2008). The fragile $\mathrm{X}$ syndrome protein represses activity-dependent translation through CYFIP1, a new 4E-BP. Cell 134, 1042-1054.

Narayanan, U., Nalavadi, V., Nakamoto, M., Thomas, G., Ceman, S., Bassell, G. J., et al. (2008). S6K1 phosphorylates and regulates fragile $\mathrm{X}$ mental retardation protein (FMRP) with the neuronal protein synthesis-dependent mammalian target of rapamycin (mTOR) signaling cascade. J. Biol. Chem. 283, 18478-18482.

Natera-Naranjo, O., Aschrafi, A., Gioio, A. E., and Kaplan, B. B. (2010). Identification and quantitative analyses of microRNAs located in the distal axons of sympathetic neurons. RNA 16, 1516-1529.

Pan, L., Zhang, Y. Q., Woodruff, E., and Broadie, K. (2004). The Drosophila fragile $\mathrm{X}$ gene negatively regulates neuronal elaboration and synaptic differentiation. Curr. Biol. 14, 1863-1870.

Paquin, N., Menade, M., Poirier, G., Donato, D., Drouet, E., and Chartrand, P. (2007). Local activation of yeast ASH1 mRNA translation through phosphorylation of Khdlp by the casein kinase Ycklp. Mol. Cell 26, 795-809.

Patturajan, M., Wei, X., Berezney, R., and Corden, J. L. (1998). A nuclear matrix protein interacts with the phosphorylated C-terminal domain of RNA polymerase II. Mol. Cell. Biol. 18, 2406-2415.

Pellizzoni, L., Yong, J., and Dreyfuss, G. (2002). Essential role for the SMN complex in the specificity of snRNP assembly. Science 298, 1775-1779.

Perycz, M., Urbanska, A. S., Krawczyk, P. S., Parobczak, K., and Jaworski, J. (2011). Zipcode binding protein 1 regulates the development of dendritic arbors in hippocampal neurons. J. Neurosci. 31, 5271-5285.

Piazzon, N., Rage, F., Schlotter, F., Moine, H., Branlant, C., and Massenet, S. (2008). In vitro and in cellulo evidences for association of the survival of motor neuron complex with the fragile $\mathrm{X}$ mental 
retardation protein. J. Biol. Chem. 283, 5598-5610.

Pinter, R., and Hindges, R. (2010). Perturbations of microRNA function in mouse dicer mutants produce retinal defects and lead to aberrant axon pathfinding at the optic chiasm. PLoS ONE 5:e10021. doi: 10.1371/journal.pone.0010021

Piper, M., Anderson, R., Dwivedy, A., Weinl, C., Van Horck, F., Leung, K. M., et al. (2006). Signaling mechanisms underlying Slit2induced collapse of Xenopus retinal growth cones. Neuron 49, 215-228.

Price, T. J., Flores, C. M., Cervero, F., and Hargreaves, K. M. (2006). The RNA binding and transport proteins staufen and fragile $\mathrm{X}$ mental retardation protein are expressed by rat primary afferent neurons and localize to peripheral and central axons. Neuroscience 141, 2107-2116.

Richter, J. D. (2007). CPEB: a life in translation. Trends Biochem. Sci. 32, 279-285.

Rossoll, W., Jablonka, S., Andreassi, C., Kroning, A. K., Karle, K., Monani, U. R., et al. (2003). Smn, the spinal muscular atrophy-determining gene product, modulates axon growth and localization of betaactin mRNA in growth cones of motoneurons. J. Cell Biol. 163, 801-812.

Rossoll, W., Kroning, A. K., Ohndorf, U. M., Steegborn, C., Jablonka, S., and Sendtner, M. (2002). Specific interaction of Smn, the spinal muscular atrophy determining gene product, with hnRNP-R and gryrbp/hnRNP-Q: a role for Smn in RNA processing in motor axons? Hum. Mol. Genet. 11, 93-105.

Santini, E., Huynh, T. N., Macaskill, A. F., Carter, A. G., Pierre, P., Ruggero, D., et al. (2013). Exaggerated translation causes synaptic and behavioural aberrations associated with autism. Nature 493, 411-415.

Sasaki, Y., Welshhans, K., Wen, Z., Yao, J., Xu, M., Goshima, Y., et al. (2010). Phosphorylation of zipcode binding protein 1 is required for brainderived neurotrophic factor signaling of local beta-actin synthesis and growth cone turning. J. Neurosci. 30, 9349-9358.

Schratt, G. M., Tuebing, F., Nigh, E. A., Kane, C. G., Sabatini, M. E., Kiebler, M., et al. (2006). A brain-specific microRNA regulates dendritic spine development. Nature 439, 283-289.
Stains, J. P., Lecanda, F., Towler, D. A., and Civitelli, R. (2005). Heterogeneous nuclear ribonucleoprotein $\mathrm{K}$ represses transcription from a cytosine/thymidine-rich element in the osteocalcin promoter. Biochem. J. 385, 613-623.

Swanger, S. A., and Bassell, G. J. (2011). Making and breaking synapses through local mRNA regulation. Curr. Opin. Genet. Dev. 21, 414-421.

Taylor, A. M., Berchtold, N. C., Perreau, V. M., Tu, C. H., Li Jeon, N., and Cotman, C. W. (2009). Axonal mRNA in uninjured and regenerating cortical mammalian axons. J. Neurosci. 29, 4697-4707.

Taylor, A. M., Wu, J., Tai, H. C., and Schuman, E. M. (2013). Axonal translation of beta-catenin regulates synaptic vesicle dynamics. J. Neurosci. 33, 5584-5589.

Tcherkezian, J., Brittis, P. A., Thomas, F., Roux, P. P., and Flanagan, J. G. (2010). Transmembrane receptor DCC associates with protein synthesis machinery and regulates translation. Cell 141, 632-644.

Tessier, C. R., and Broadie, K. (2008). Drosophila fragile X mental retardation protein developmentally regulates activity-dependent axon pruning. Development 135, 1547-1557.

Till, S. M., Li, H. L., Miniaci, M. C., Kandel, E. R., and Choi, Y. B. (2011). A presynaptic role for FMRP during protein synthesis-dependent longterm plasticity in Aplysia. Learn. Mem. 18, 39-48.

Ule, J., Jensen, K., Mele, A., and Darnell, R. B. (2005). CLIP: a method for identifying proteinRNA interaction sites in living cells. Methods 37, 376-386.

Verma, P., Chierzi, S., Codd, A. M., Campbell, D. S., Meyer, R. L., Holt, C. E., et al. (2005). Axonal protein synthesis and degradation are necessary for efficient growth cone regeneration. J. Neurosci. 25, 331-342.

Wang, I. F., Reddy, N. M., and Shen, C. K. (2002). Higher order arrangement of the eukaryotic nuclear bodies. Proc. Natl. Acad. Sci. U.S.A. 99 13583-13588.

Wang, Z. H., Li, S. J., Qi, Y., Zhao, J. J., Liu, X. Y., Han, Y., et al. (2011). HuD regulates the cpg15 expression via the $3^{\prime}$-UTR and AU-rich element. Neurochem. Res. 36, 1027-1036.

Welshhans, K., and Bassell, G. J. (2011). Netrin-1-induced local beta-actin synthesis and growth cone guidance requires zipcode binding protein 1 . J. Neurosci. 31, 9800-9813.
Wu, K. Y., Hengst, U., Cox, L. J., Macosko, E. Z., Jeromin, A., Urquhart, E. R., et al. (2005) Local translation of RhoA regulates growth cone collapse. Nature 436 1020-1024.

Xu, M., and Hecht, N. B. (2011). Polypyrimidine tract-binding protein 2 binds to selective, intronic messenger RNA and microRNA targets in the mouse testis. Biol. Reprod. $84,435-439$.

$\mathrm{Xu}$, X. L., Li, Y., Wang, F., and Gao, F. B. (2008). The steadystate level of the nervous-systemspecific microRNA-124a is regulated by dFMR1 in Drosophila. J. Neurosci. 28, 11883-11889.

Xu, X. L., Zong, R., Li, Z., Biswas, M. H., Fang, Z., Nelson, D. L., et al. (2011). FXR1P but not FMRP regulates the levels of mammalian brain-specific microRNA-9 and microRNA-124. J. Neurosci. 31, 13705-13709.

Yao, J., Sasaki, Y., Wen, Z., Bassell, G. J., and Zheng, J. Q. (2006). An essential role for beta-actin mRNA localization and translation in $\mathrm{Ca} 2+-$ dependent growth cone guidance. Nat. Neurosci. 9, 1265-1273.

Yin, H. H., Davis, M. I., Ronesi, J. A., and Lovinger, D. M. (2006). The role of protein synthesis in striatal long-term depression. J. Neurosci. 26, 11811-11820.

Ymlahi-Ouazzani, Q., J Bronchain, O., Paillard, E., Ballagny, C., Chesneau, A., Jadaud, A., et al. (2010). Reduced levels of survival motor neuron protein leads to aberrant motoneuron growth in a Xenopus model of muscular atrophy. Neurogenetics 11 , 27-40.

Yoon, B. C., Jung, H., Dwivedy, A., O'hare, C. M., Zivraj, K. H., and Holt, C. E. (2012). Local translation of extranuclear lamin B promotes axon maintenance. Cell 148 , 752-764.

Zhang, G., Neubert, T. A., and Jordan, B. A. (2012). RNA binding proteins accumulate at the postsynaptic density with synaptic activity. J. Neurosci. 32, 599-609.

Zhang, H., Xing, L., Rossoll, W. Wichterle, H., Singer, R. H., and Bassell, G. J. (2006). Multiprotein complexes of the survival of motor neuron protein SMN with Gemins traffic to neuronal processes and growth cones of motor neurons. J. Neurosci. 26, 8622-8632.

Zhang, H. L., Eom, T., Oleynikov, Y., Shenoy, S. M., Liebelt, D. A.,
Dictenberg, J. B., et al. (2001) Neurotrophin-induced transport of a beta-actin mRNP complex increases beta-actin levels and stimulates growth cone motility. Neuron 31, 261-275.

Zhang, H. L., Pan, F., Hong, D., Shenoy, S. M., Singer, R. H., and Bassell, G. J. (2003). Active transport of the survival motor neuron protein and the role of exon-7 in cytoplasmic localization. J. Neurosci. 23, 6627-6637.

Zhang, Y. Q., Bailey, A. M., Matthies, H. J., Renden, R. B., Smith, M. A., Speese, S. D., et al. (2001). Drosophila fragile $\mathrm{X}$-related gene regulates the MAP1B homolog Futsch to control synaptic structure and function. Cell 107, 591-603.

Zheng, J. Q., Kelly, T. K., Chang, B., Ryazantsev, S., Rajasekaran, A. K., Martin, K. C., et al. (2001). A functional role for intra-axonal protein synthesis during axonal regeneration from adult sensory neurons. J. Neurosci. 21, 9291-9303.

Zivraj, K. H., Tung, Y. C., Piper, M., Gumy, L., Fawcett, J. W., Yeo, G. S. et al. (2010). Subcellular profiling reveals distinct and developmentally regulated repertoire of growth cone mRNAs. J. Neurosci. 30, 15464-15478.

Conflict of Interest Statement: The authors declare that the research was conducted in the absence of any commercial or financial relationships that could be construed as a potential conflict of interest.

Received: 01 February 2013; paper pending published: 23 March 2013; accepted: 06 May 2013; published online: 23 May 2013.

Citation: Hörnberg H and Holt C (2013) RNA-binding proteins and translational regulation in axons and growth cones. Front. Neurosci. 7:81. doi: 10.3389/fnins. 2013.00081

This article was submitted to Frontiers in Neurogenomics, a specialty of Frontiers in Neuroscience.

Copyright (c) 2013 Hörnberg and Holt. This is an open-access article distributed under the terms of the Creative Commons Attribution License, which permits use, distribution and reproduction in other forums, provided the original authors and source are credited and subject to any copyright notices concerning any third-party graphics etc. 